Check for updates

Cite this: RSC Adv., 2017, 7, 53433

Received 9th October 2017

Accepted 8th November 2017

DOI: $10.1039 / c 7 r a 11103 g$

rsc.li/rsc-advances

\section{Simultaneous removal of heavy metals and biodegradation of organic matter with sediment microbial fuel cells}

\begin{abstract}
M. S. Wu, iD ${ }^{* a}$ X. Xu, ${ }^{b}$ Q. Zhao and Z. Y. Wang ${ }^{a}$
To in situ remediate rivers polluted by organic matter and heavy metals, lab-scale sediment microbial fuel cells (SMFCs) were operated under different conditions. Results showed that the operation of SMFCs with anoxic cathodes contributed to the reductive reactions of $\mathrm{Hg}(॥), \mathrm{Cu}(॥)$ and $\mathrm{Ag}(\mathrm{I})$ in overlying water and obtained the highest removal efficiencies $(97.3 \pm 2.6 \%$ of $\mathrm{Hg}(॥), 87.7 \% \pm 3.2 \%$ of $\mathrm{Cu}(॥)$ and $98.5 \pm 1.2 \%$ of $\mathrm{Ag}(\mathrm{I}))$ after 60 days' operation. Additionally, the SMFCs effectively enhanced the biodegradation of organic matter in the sediment and generated electricity. High-throughput sequencing of anodic microbial communities indicated that electrogenic bacteria and fermentative bacteria coexisted in the chamber and the operation of SMFC increased the content of electrogenic bacteria in the anodic chamber.
\end{abstract}

\section{Introduction}

Rivers and lakes are important for human living due to their roles in the water landscape, flood mitigation and water supply. ${ }^{1}$ Unfortunately, as a pervasive ramification of poorly planned industrialization, large amounts of wastewater containing organic matter and toxic heavy metals are discharged into rivers and lakes, which poses a serious threat to ecosystems and human health. In comparison with the increase of organic matter in water and sediment that has been recognized as a formidable environmental issue ${ }^{2}$ heavy metal pollution has even greater detrimental consequences as it is characterized by high toxicity, non-biodegradability and bio-accumulation. ${ }^{3}$ Therefore, it can be assumed that the environmental damage of a water body due to heavy metals can be alleviated by adopting a method for modulating their valence state which is essential for their removal and recovery. Extensive efforts have been expended on developing techniques such as physical, chemical and biological methods for either removing or remediating pollution caused by the existence of heavy metals in water bodies, but such efforts can be ineffective or expensive especially when tackling low concentration heavy metals. ${ }^{4}$

Microbial fuel cell (MFC), as a bio-electrochemical system, integrates bacterial metabolism and electrochemical process to convert chemical energy to electrical energy. ${ }^{5}$ In the MFC, organic compounds are degraded by microbes attached on anode, and the electrons are transferred to the cathode through the external circuit. At the same time, oxygen as the terminal

${ }^{a}$ College of Resources and Civil Engineering, Northeastern University, Shenyang 100819, China. E-mail: wumingsong@163.com; 389045993@qq.com; 1328118192@qq.com; Tel: +863358057478

${ }^{b}$ Tongji Zhejiang College, 314051, China. E-mail: xuxunhit@126.com electron acceptor was reduced to water by electrons at the cathod. ${ }^{6}$ In addition to oxygen, some oxides such as nitrate, sulfate can also function as terminal electron acceptors in MFCs. As we know, some metal ions can actually substitute for oxygen and serve as effective terminal electron acceptors in MFCs. ${ }^{7}$ Therefore, with organic matter in the anodic chamber often used as electron donors, the electron acceptors can be selected from oxygen, metal ions and other oxides in MFCs in accordance with the purpose of operating MFCs. An investigation of the feasibility of in situ electrokinetic remediation for toxic metal contaminated soil driven by MFC revealed that the removal efficiencies of $31.0 \%$ and $44.1 \%$ for $\mathrm{Cd}$ and $\mathrm{Pb}$ at the anode region could be achieved after about 143 days and 108 days' operation. ${ }^{8}$ Zhang et al. ${ }^{9}$ constructed MFCs using $\mathrm{Cr}(\mathrm{vI})$ and $\mathrm{Cu}$ (II) as terminal electron acceptors to harvest electricity energy for Cd(II) removal, and $41.4 \pm 2.2 \%$ of $\mathrm{Cd}(\mathrm{II})$, along with $56.4 \pm 0.5 \%$ of $\mathrm{Cr}(\mathrm{VI})$ and $52.7 \pm 3.5 \%$ of $\mathrm{Cu}$ (II), was removed. Therefore, MFC is a promising technology, in which metal ions can be transformed in the anaerobic or anoxic cathode, while organic compounds are used as the electron donor in the anodic chamber. ${ }^{7}$

To date, the researches on toxic heavy metals remediation using MFCs mostly focused on soil and wastewater and few reports have investigated simultaneous in situ remediation of organic matter and heavy metals pollution in rivers and lakes. Additionally, artificial nutrient solution containing the organic compounds was often added into anodic chamber as the carbon source and the anode also need inoculated bacteria before operation, which made it hard to apply the remediation technology to practical engineering. ${ }^{8}$ In the present study, SMFCs which has great potential to be scaled up for practical application, was constructed to remediate the sediment and overlying water polluted by organic matter and heavy metals. Three typical 
heavy metals ( $\mathrm{Hg}$, $\mathrm{Cu}$ and $\mathrm{Ag}$ ), which are included in the US EPA priority pollutants list and are of great environmental significance, were chosen as representative heavy metals and their removal and stabilization are investigated in this study. ${ }^{\mathbf{1}}$ The aim of the present study was to (1) investigate the removal and recovery of heavy metals in overlying water; (2) compare the variations of organic matter in SMFCs under different conditions with electricity generated; (3) understand the pathway and microbial mechanism of heavy metals removal and recovery in SMFC.

\section{Materials and methods}

\section{Samples collection and preparation}

The sediment and overlying water samples were collected from the downstream of a river, a discharge outlet of urban sewage plant in Hebei Province, China. In order to remove large gravels from the sediment samples, the samples were sieved through a $0.5 \mathrm{~cm}$ sieve which removes coarse debris, and were mechanically homogenized. During the operation, overlying water samples were collected for determination of the concentrations of metals. Sediment samples near the anode were collected at both the beginning and end of the operations when the sediment samples at the surfaces were discarded, and the other samples from different depths were mechanically homogenized for further analysis. Dissolved organic matter (DOM) extraction of the sediment was conducted in the same way as in the previous study. ${ }^{10}$ The measured total organic carbon (TOC) and dissolved organic carbon (DOC) of the sediments were $92.51 \pm 3.44 \mathrm{~g} \mathrm{~kg}^{-1}$ dry sediment and $8.73 \pm 1.05 \mathrm{~g} \mathrm{~kg}^{-1}$ dry sediment, respectively. The initial concentrations of $\mathrm{Hg}$ (II), $\mathrm{Cu}(\mathrm{II})$ and $\mathrm{Ag}(\mathrm{I})$ in the overlying water are $0.00148 \pm 0.00012$, $0.658 \pm 0.015$ and $0.28 \pm 0.07 \mathrm{mg} \mathrm{L}^{-1}$, which were obtained by adding $\mathrm{HgCl}_{2}, \mathrm{CuCl}_{2}$ and $\mathrm{AgNO}_{3}$, respectively.

\section{SMFCs construction and operation}

The schematic of the design for the SMFC was the same as given in the previous study. ${ }^{10}$ Three single chamber bioreactors (BRs) were constructed with plexiglass, which were named BR1, BR2 and BR3. Each BR reactor was constructed with an inner diameter of $10 \mathrm{~cm}$ and height of $50 \mathrm{~cm}$. BR1 was designed as control to imitate the natural condition without connected electrodes, while BR2 and BR3 were designed under closed circuit condition. The difference between BR2 and BR3 was the oxygen concentration in cathodic chambers. In BR2, the oxygen in cathodic chamber was from the atmosphere. The cathodic chamber of BR3 was controlled under anoxic condition, which was achieved by sparging $\mathrm{N}_{2}$ gas into the chamber for $15 \mathrm{~min}$ and covering the chamber with plastic film. Water loss via evaporation was replenished with distilled water. The bioreactors were first filled with $10 \mathrm{~cm}$ height wet sediment which was then covered with $30 \mathrm{~cm}$ height prepared water sample. The anode and cathode was made of graphite fiber and had a surface area of $1.5 \mathrm{~m}^{2} \mathrm{~g}^{-1}$. Two graphite fiber brushes $(5 \mathrm{~cm}$ diameter $\times 10 \mathrm{~cm}$ length) were placed in the anodic and cathodic chambers, respectively, serving as the electrodes. The anodic graphite fiber brush has a surface area $7.254 \mathrm{~m}^{2}$. The anode and cathode were connected with an external resistance of $1000 \Omega$ during the operations, and the distance between two electrodes was $32.5 \mathrm{~cm}$.

\section{Analytical methods}

The fluorescent property of DOM in sediment was measured using excitation-emission matrix (EEM), a spectrofluorometer (FP-6500, JASCO, Japan). The excitation wavelengths range was set from 220 to $500 \mathrm{~nm}$ in $5 \mathrm{~nm}$ increments. The emission wavelength range was set from 220 to $650 \mathrm{~nm}$ in $1 \mathrm{~nm}$ increments.

The concentrations of $\mathrm{Hg}$ (II), $\mathrm{Cu}$ (II) and $\mathrm{Ag}$ (I) were analyzed using Inductively Coupled Plasma (ICP) Spectroscopy (Optimas 5300, Perkin-Elmer, USA). Each experiment was performed in
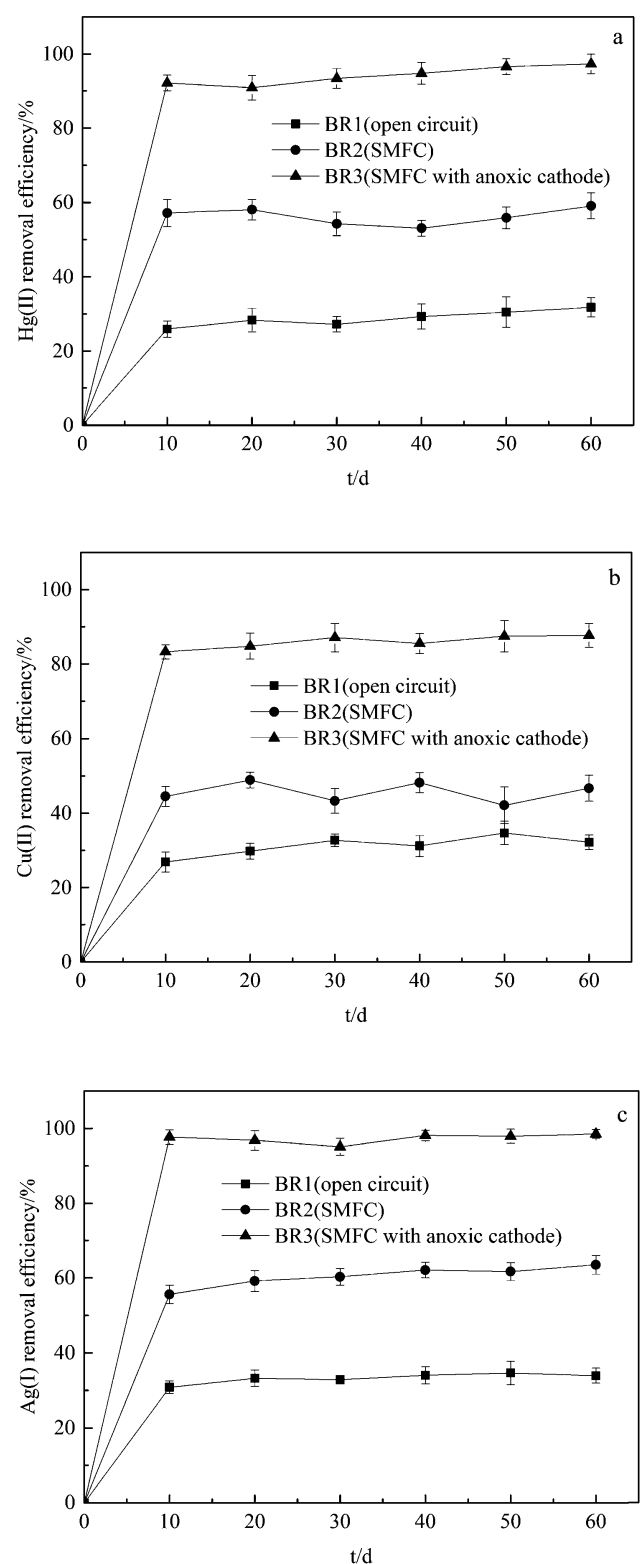

Fig. 1 The removal efficiencies of (a) $\mathrm{Hg}(॥),(b) \mathrm{Cu}(॥)$ and (c) $\mathrm{Ag}($ () in overlying water after the operation of BRs. 
duplicate, and the statistical significance of the differences was determined according to the variance analysis using the Origin program (OriginPro8.0, USA).

The cell voltages of the SMFCs were measured using a data acquisition system (12 bit A/D-conversion chips, US), and was recorded every $1 \mathrm{~min}$. The power density was calculated according to the equation $P=U_{\text {cell }} \times I / A$, where $U_{\text {cell }}$ is the cell voltage $(\mathrm{V}), I$ is the current $(\mathrm{A})$, and $A$ is the total anode surface $\left(\mathrm{m}^{2}\right)$. Polarization studies were performed by adjusting external resistor from 10 to $99999.9 \Omega$ and determining the maximum power density after allowing the circuit to stabilize for $10 \mathrm{~min}$ at each resistance.

\section{Results and discussion}

\section{Removal and recovery of $\mathrm{Hg}$ (II), $\mathrm{Cu}(\mathrm{II})$ and $\mathrm{Ag}(\mathrm{I})$ in overlying water in SMFCs}

The overlying water samples were tested at intervals of 10 days. The removal efficiencies of $\mathrm{Hg}$ (II), $\mathrm{Cu}$ (II) and $\mathrm{Ag}$ (I) are illustrated in Fig. 1.

As seen in Fig. 1, the removal of $\mathrm{Hg}$ (II), $\mathrm{Cu}$ (II) and $\mathrm{Ag}$ (I) in overlying water were obvious and showed similar curves in BR2 and BR3. The use of SMFCs can effectively remove the $\mathrm{Hg}$ (II), $\mathrm{Cu}$ (II) and $\mathrm{Ag}$ (I) in cathodic chamber, and the SMFC with anoxic cathode obtained higher removal efficiencies. The $\mathrm{Hg}$ (II), $\mathrm{Cu}(\mathrm{II})$ and $\mathrm{Ag}(\mathrm{I})$ removal rates in SMFC with anoxic cathode after 60 days' operation reached $97.3 \pm 2.6 \%, 87.7 \% \pm 3.2 \%$ and $98.5 \pm$ $1.2 \%$, which indicated that oxygen as terminal electron acceptor can compete with metal ions and affect their removal rates. After the operation of SMFC with anoxic cathode, the concentrations of $\mathrm{Hg}$ (II), $\mathrm{Cu}(\mathrm{II})$ and $\mathrm{Ag}(\mathrm{I})$ in overlying water were reduced to $0.00004 \pm 0.000005,0.081 \pm 0.008$ and $0.0042 \pm$ $0.0009 \mathrm{mg} \mathrm{L}^{-1}$, which are lower than the levels stated in the secondary standard of environmental quality standards for surface water (GB3838-2002, China).

In the present SMFC system, the electrons produced by the degradation of organic matter in the sediment are delivered via wire to cathode, and the oxygen, metal ions or other oxides compete to be terminal electron acceptors. The mechanisms of metals removal in cathodic chamber by SMFC include, but are not limited to bioreduction, biosorption, bioaccumulation and biomineralization. ${ }^{7}$ As is shown in Fig. 1, the removal rates of $\mathrm{Hg}(\mathrm{II}), \mathrm{Cu}(\mathrm{II})$ and $\mathrm{Ag}(\mathrm{I})$ under open circuit condition could achieve $25-35 \%$ mainly due to the effect of biosorption and bioaccumulation. ${ }^{7,11}$ Abourached et al., ${ }^{11}$ who constructed singlechamber microbial fuel cells for the removal of cadmium and zinc, showed that biosorption and sulfides precipitation were the main mechanisms for heavy metals removal. Wang et al. ${ }^{12}$ demonstrated that $\mathrm{Cr}(\mathrm{vI})$ in soil can be removed as the electron acceptor using MFC-based technology. As the difference between the removal rates obtained under open circuit condition and those achieved by SMFC indicates, the operation of SMFC more than doubled the removal efficiency of heavy metals, which showed that bioreduction achieved the most significant effect in terms of the removal of heavy metals among the major biological mechanisms of metal removal.
The redox potentials of $\mathrm{Hg}$ (II) $/ \mathrm{Hg}, \mathrm{Cu}(\mathrm{II}) / \mathrm{Cu}, \mathrm{Ag}$ (I) $/ \mathrm{Ag}$ and $\mathrm{O}_{2} /$ $\mathrm{H}_{2} \mathrm{O}$ couples are $0.91,0.28,0.79$ and $1.23 \mathrm{~V}$, respectively. ${ }^{7}$ The half-cell $\mathrm{Hg}$ (II) reductive reaction has a redox potential of
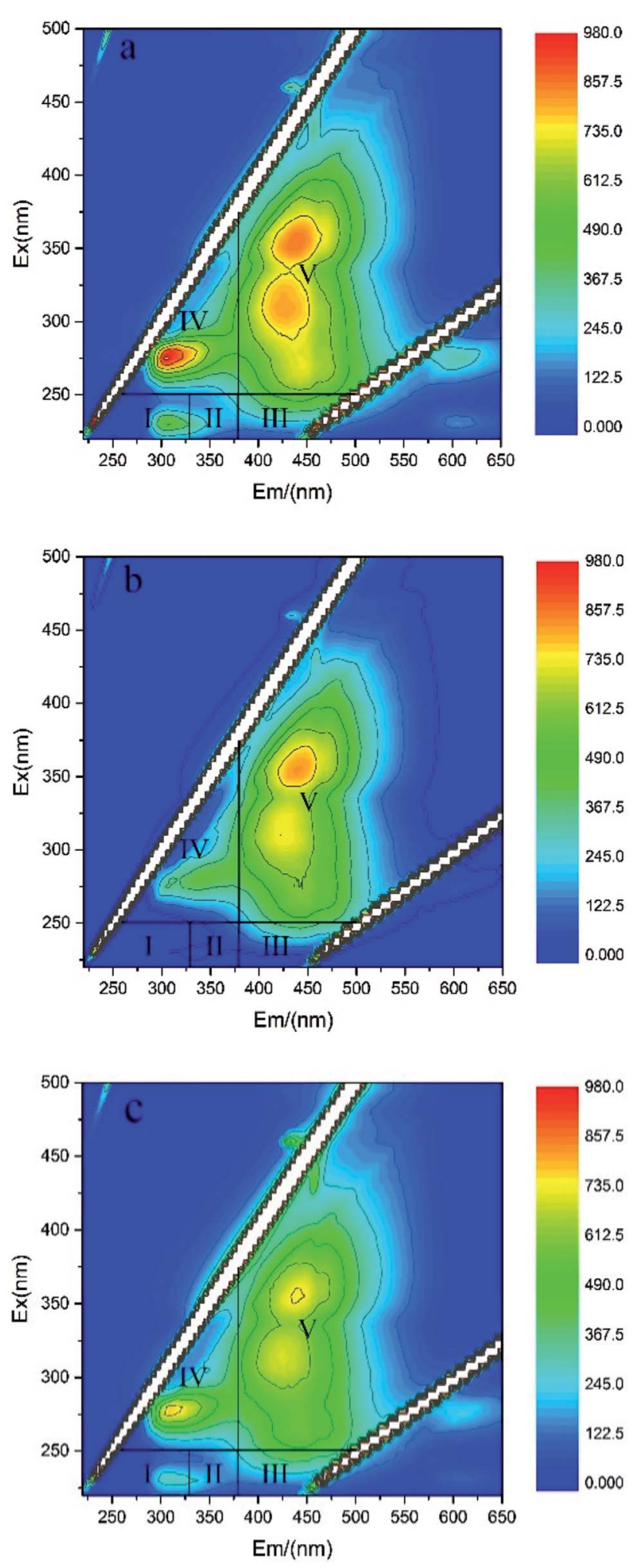

Fig. 2 The EEM spectra of the DOM in sediments after 60 day's operation of BRs (a) under open circuit condition, (b) SMFC, (c) SMFC with anoxic cathode. 
$+0.91 \mathrm{~V}$, slightly lower than $\mathrm{O}_{2}$, which means $\mathrm{Hg}$ (II) is likely to act as a terminal electron acceptor in cathodic chamber. Therefore, $\mathrm{Hg}$ (II) in the overlying water can be reduced to $\mathrm{Hg}(0)$ in the presence of an organic electron donor. Wang et al. ${ }^{13}$ reported a removal efficiency of more than $98 \% \mathrm{Hg}$ (II) achieved within $10 \mathrm{~h}$ when investigating cathodic reduction of $\mathrm{Hg}$ (II) in a dual-chamber MFC that used acetate as the electron donor. The cathodic reduction of $\mathrm{Cu}(\mathrm{II})$ to $\mathrm{Cu}(0)$ can occur spontaneously in a MFC, ${ }^{7}$ but the results of the present study indicated that the reductive reaction was restrained when oxygen was existent in cathode. Copper recovery from $\mathrm{Cu}$ (II) solution can be realized at different initial $\mathrm{Cu}(\mathrm{II})$ concentrations with anoxic cathode and over $90 \%$ of $\mathrm{Cu}(\mathrm{II})$ removal rate can be achieved. ${ }^{\mathbf{1 4}}$ $\mathrm{Ag}$ (I) offers a likely TEA at the cathode of the MFC, which achieves the precipitation of metallic $\operatorname{Ag}(0)$ through the reduction of $\operatorname{Ag}(\mathrm{I})$ ions due to the positive standard redox potential $(0.799 \mathrm{~V})$ of $\mathrm{Ag}(\mathrm{I})$. Choi and $\mathrm{Cui}^{15}$ investigated the cathodic reduction of $\mathrm{Ag}$ (I) from an $\mathrm{AgNO}_{3}$ solution in a dual-chamber MFC, in which acetate was used as the electron donor, and noted silver removal efficiencies of $>99 \%$ obtained within $8 \mathrm{~h}$ with initial concentrations variating from 50 to $200 \mathrm{mg} \mathrm{L}^{-1} \mathrm{Ag}(\mathrm{I})$ ion. The results in present study suggested that SMFC is an effective method for water remediation polluted by $\mathrm{Hg}$ (II), $\mathrm{Cu}$ (II) and $\operatorname{Ag}(\mathrm{I})$. But biological treatment of water polluted by toxic metals is still challenging because toxic metals can affect DNA and viability of microorganisms. ${ }^{16}$

\section{Variations of organic matter within sediment in SMFCs}

The organic matter in sediment can be degraded as electron donor during the operation of SMFC. The EEM spectra of the DOM from sediments in BR1-BR4 after 60 days' operation are shown in Fig. 2, which can characterize organic matter in sediments.

Peaks appearing at different regions are related to different organics. There exist five regions according to previous study: ${ }^{17}$ (I) excitation wavelengths $(220-250 \mathrm{~nm})$ and emission wavelengths (280-330 nm); (II) excitation wavelengths (220-250 nm) and emission wavelengths (330-380 nm), with both regions related to the aromatic residues in proteins such as tyrosine and tryptophan; (III) excitation wavelengths (220-250 nm) and emission wavelengths (380-480 nm), which suggests fulvic acidlike substances; (IV) excitation wavelengths (250-360 nm) and emission wavelengths (280-380 nm), which is related to soluble microbial byproduct-like compounds; (V) excitation wavelengths (250-420 $\mathrm{nm}$ ) and emission wavelengths (380-520 nm), which is related to humic acid-like organics.

As seen in Fig. 2, in comparison with the open circuit control, the intensities of regions III, IV and V were decreased by operation of the SMFCs, which indicated that fulvic acid-like substances, soluble microbial byproduct-like compounds and humic acid-like organic compounds in sediments were degraded by electrogenic bacteria attached on the film of anodes. ${ }^{17}$ The biodegradation in SMFC was more obvious than that in the SMFC with anoxic cathode, which was consistent with the power output discussed in the following section. The variations of organic matter showed that they can be used as
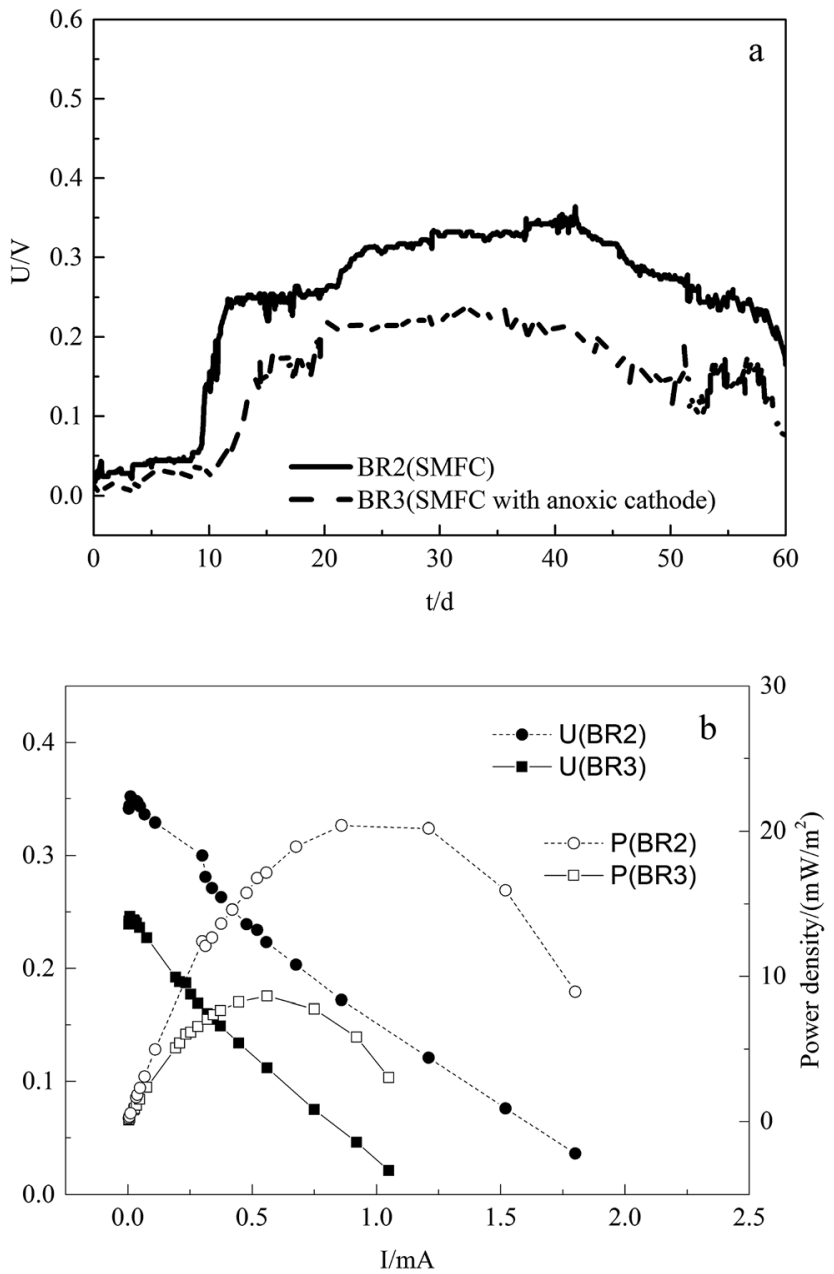

Fig. 3 Voltages (a), power density and polarization curves (b) of SMFCs.

electron donor that provides electrons to metal ions, oxygen or other oxides essential to electricity generation.

\section{Electricity generation in SMFCs}

The power output is related to the alteration of properties in anode and the reductive reactions in cathode. BR2 and BR3 were applied to study electricity generation by the SMFCs under different conditions. The cell voltages during the operation of the SMFCs are illustrated in Fig. 3a, and Fig. 3b illustrates the power densities and polarization curves of the SMFCs measured on the 30th day (stable period).

As seen in Fig. 3, the cell voltages of SMFCs gradually increased after the start-up, and decreased significantly during the last 10 days. The $V_{\max }$ of BR2 and BR3 were 0.351 and $0.239 \mathrm{~V}$, and the corresponding $P_{\max }$ were 20.98 and $8.79 \mathrm{~W} \mathrm{~m}^{-2}$, respectively, which were lower than was reported in previous studies. ${ }^{10}$ Deng et $a .^{18}$ operated single-chamber microbial fuel cells using soil organic matter as a fuel source and obtained different power output at different temperatures and depths of soil. In this study, the lower power output could be attributed to the acute toxicity of metals, which decreases the 


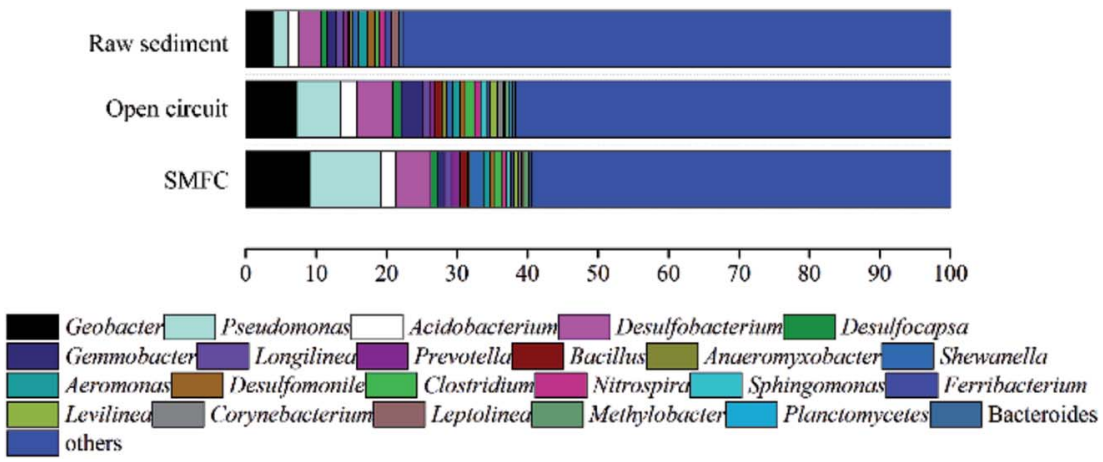

Fig. 4 Genus distributions of the microbial communities in sediment and anodic biofilm.

species richness and inhibits the growth and activity of microorganisms. ${ }^{19}$ In comparison with the power output of SMFCs under two conditions, the SMFC with anoxic cathode obtained lower cell voltage and power density, which was consistent with the biodegradation of organic matter. In the sediment of the SMFC, organic compounds were degraded by microorganisms and the electrons were conducted to the anode or directly utilized by the oxides in sediment, and then the anodic electrons were delivered to cathode via wire, which produced current and voltage. Therefore, the power output can be affected by the organic matter or oxides in sediment and the reductive reactions in overlying water, which accounts for the lower voltage and power density in SMFC which lacks oxygen as electron acceptor.

\section{Microbial communities analysis in sediments and anodic biofilm}

High-throughput sequencing of the 16S rRNA gene was used to analyze the anodic microbial communities. The samples for the microbial communities analysis were taken from the raw sediment, anodic biofilm of BR1 (open circuit), BR2 (SMFC) after 60 days' operation.

Fig. 4 indicates that, at the genus level, Pseudomonas is the most predominant genus $(10.06 \%)$ in the BR2 (SMFC) and Geobacter the secondary (9.11\%). Pseudomonas and Geobacter species are known to produce current in various MFCs. ${ }^{20} \mathrm{In}$ light of a comparison between BR1 (open circuit) and BR2 (SMFC), it is learnt that the relative abundance of genera Geobacter increased from $7.24 \%$ to $9.11 \%$ with genera Pseudomonas increasing from $6.21 \%$ to $10.06 \%$. In accordance with these results, the operation of SMFC is responsible for the change of the community structures and the increase in the content of electrogenic bacteria of anodic chamber. Fig. 4 also confirms the coexistence of electrogenic bacteria and fermentative bacteria in the anodic chambers and reveals the same microbial community structures as reported by the previous study which does not involve the treatment of heavy metals. ${ }^{10}$ Fermentative bacteria in the anodic chambers are generally believed to essential to the successful conversion of big complex molecules into small simple molecules, which electrogenic bacteria feed on. As is revealed in the observed trends in power output, fermentation products can be fully oxidized by electrogenic bacteria using an anodic electron acceptor.

Pathways of organic matter degradation and metals removal in SMFCs

According to the results of the present study, the remediation of $\mathrm{Hg}$ (II), $\mathrm{Cu}(\mathrm{II})$ and $\mathrm{Ag}(\mathrm{I})$ in overlying water can be achieved with the biodegradation of sediment organic matter and electricity generation. The pathways of organic matter degradation and metals removal was shown in Fig. 5.

In the sediment (anodic chamber), the organic matter was oxidized into $\mathrm{CO}_{2}$, electrons and protons by the electrogenic microorganisms attached on the anode, which has been proved by the microbial communities analysis. $\mathrm{CO}_{2}$ and protons were released, while the electrons were conducted to the solid electron acceptor, the anode. These electrons then flowed via the external wire to the cathode, which generated power output (Fig. 5).

In overlying water (cathodic chamber), the function of terminal electron acceptor is crucial, especially when metal ions remediation is considered as a main objective. The chance that some metal ions can substitute for oxygen serving as terminal electron acceptor is dependent on their redox potential. The possible reductive reactions of $\mathrm{Hg}(\mathrm{II}), \mathrm{Cu}(\mathrm{II}), \mathrm{Ag}(\mathrm{I})$ and $\mathrm{O}_{2}$ in cathode were shown in eqn (1)-(4):

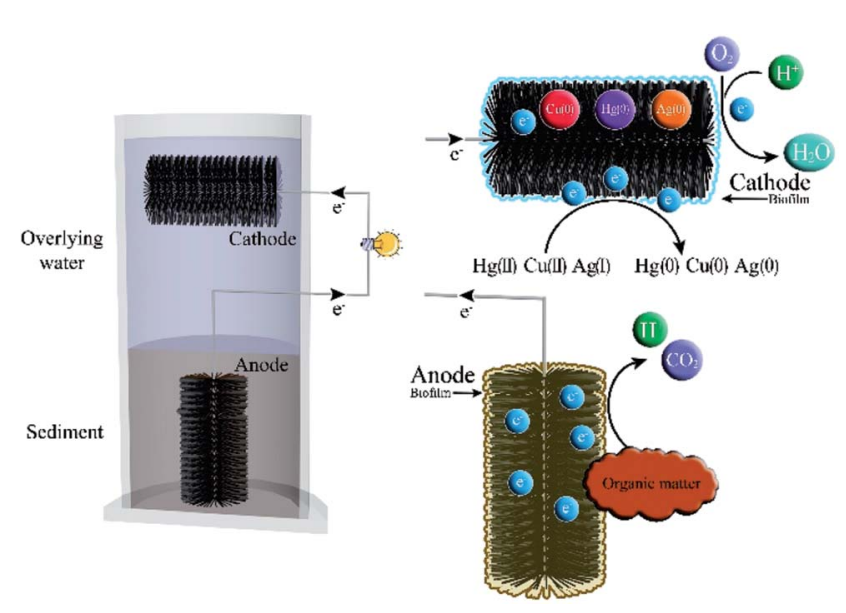

Fig. 5 The pathway of heavy metals transformation in SMFCs. 


$$
\begin{gathered}
\mathrm{Hg}^{2+}+2 \mathrm{e}^{-} \rightarrow \mathrm{Hg} \quad E^{0}=0.91 \mathrm{~V} \\
\mathrm{Cu}^{2+}+2 \mathrm{e}^{-} \rightarrow \mathrm{Cu} \quad E^{0}=0.28 \mathrm{~V} \\
\mathrm{Ag}^{+}+\mathrm{e}^{-} \rightarrow \mathrm{Ag} \quad E^{0}=0.79 \mathrm{~V} \\
4 \mathrm{H}^{+}+\mathrm{O}_{2}+4 \mathrm{e}^{-} \rightarrow 2 \mathrm{H}_{2} \mathrm{O} \quad E^{0}=1.23 \mathrm{~V}
\end{gathered}
$$

While high redox potential may compete with oxygen on the cathode to accept electrons, the low redox potential of $\mathrm{Cu}(\mathrm{II}) / \mathrm{Cu}$ makes its reduction into elemental metal difficult. It is difficult for $\mathrm{Hg}$ (II), $\mathrm{Cu}$ (II) and $\mathrm{Ag}$ (I) to compete with oxygen on the cathode due to the high cathode potential set by oxygen. Therefore, the anoxic cathode of SMFC should be used to promote the reactions to occur.

As we know, the pollutants in sediment can diffuse into overlying water under certain conditions, and vice versa. The sediment and the suspended cathode play important roles in heavy metals adsorption, desorption and dissolution, and sedimentation processes. ${ }^{21}$ The produced elemental $\mathrm{Hg}, \mathrm{Cu}$ and $\mathrm{Ag}$ in the overlying water can be removed when precipitating on the surface of cathode or sediment. Therefore, the metals can be recovered from overlying water by bioreduction. In addition to the reductive reaction, biosorption by the microorganisms grown on the cathode is another crucial process for $\mathrm{Hg}$ (II), $\mathrm{Cu}(\mathrm{II})$ and $\mathrm{Ag}$ (I) removal in the overlying water. $^{11}$

\section{Conclusions}

In this study, the SMFCs were operated to remediate the metals in overlying water and organic matter in sediment. Higher removal rates of $\mathrm{Hg}$ (II), $\mathrm{Cu}(\mathrm{II})$ and $\mathrm{Ag}$ (I) were observed in the overlying water of SMFCs that generated electricity than those under the open circuit condition. The operation of SMFCs also contributed to the reduction of the risk of pollution related to organic matter in sediment. This study illustrates the effectiveness of SMFC in biodegrading organic matter and removing heavy metals and offers a promising method for in situ remediation of rivers.

\section{Conflicts of interest}

There are no conflicts to declare.

\section{Acknowledgements}

The authors gratefully acknowledge funding from Projects E2015501080 supported by Natural Science Foundation for Youths of Hebei Province of China.

\section{Notes and references}

1 F. Li, H. Zhang, X. Meng, L. Chen and D. Yin, J. Environ. Sci., 2012, 24, 1934.
2 N. B. Grimm, D. Foster, P. Groffman, J. M. Grove, C. S. Hopkinson, K. J. Nadelhoffer and D. E. Patiki, Front. Ecol. Environ., 2008, 6, 264.

3 (a) N. Bolan, A. Kunhikrishnan, R. Thangarajan, J. Kumpiene, J. Park, T. Makino, M. B. Kirkham and K. Scheckel, J. Hazard. Mater., 2014, 266, 141; (b) H. J. Guo, S. L. Luo, C. Liang, X. Xiao, Q. Xi, W. Wei, G. Zeng, C. Liu, Y. Wan, J. Chen and Y. He, Bioresour. Technol., 2010, 101, 8599.

4 (a) J. Wang and C. Chen, Biotechnol. Adv., 2009, 27, 195; (b) T. Ghnaya, I. Slama, D. Messedi, C. Grignon, M. H. Ghorbel and C. Abdelly, Chemosphere, 2007, 67, 72; (c) S. S. Ahluwalia and D. Goyal, Bioresour. Technol., 2007, 98, 2243.

5 (a) B. E. Logan, B. Hamelers, R. A. Rozendal, U. Schrorder, J. Keller, S. Freguia, P. Aelteman, W. Verstraete and K. Rabaey, Environ. Sci. Technol., 2006, 40, 5181; (b) B. E. Logan, Nat. Rev. Microbiol., 2009, 7, 375.

6 J. Xu, G. P. Sheng, H. W. Luo, W. W. Li, L. F. Wang and H. Q. Yu, Water Res., 2012, 46, 1817.

7 Y. V. Nancharaiah, M. S. Venkata and P. N. Lens, Bioresour. Technol., 2015, 195, 173.

8 N. Habibul, Y. Hu and G. P. Sheng, J. Hazard. Mater., 2016, 318, 9.

9 Y. Zhang, L. Yu, D. Wu, L. Huang, P. Zhou, X. Quan and G. Chen, J. Power Sources, 2015, 273, 1103.

$10 \mathrm{X} . \mathrm{Xu}, \mathrm{Q}$. Zhao and M. Wu, Bioresour. Technol., 2017, 225, 402.

11 C. Abourached, T. Catal and H. Liu, Water Res., 2014, 51, 228.

12 C. Wang, H. Deng and F. Zhao, Soil Sediment Contam., 2016, $25,1$.

13 Z. Wang, B. Lim and C. Choi, Bioresour. Technol., 2011, 102, 6304.

14 (a) H. C. Tao, M. Liang, W. Li, L. J. Zhang, J. R. Ni and W. M. Wu, J. Hazard. Mater., 2011, 189, 186; (b) H. C. Tao, L. J. Zhang, Z. Y. Gao and W. M. Wu, Bioresour. Technol., 2011, 102, 10334.

15 C. Choi and Y. Cui, Bioresour. Technol., 2012, 107, 522.

16 Z. Sheng, C. Wei, C. Liao and H. Wu, J. Environ. Sci., 2008, 20, 1514.

17 (a) X. Xu, Q. Zhao, M. Wu, J. Ding and W. Zhang, Bioresour. Technol., 2017, 225, 402; (b) W. Chen, P. Westerhoff, J. A. Leenheer and K. Booksh, Environ. Sci. Technol., 2003, 37, 5701.

18 H. Deng, Y. Wu, F. Zhang, Z. Huang, Z. Chen, H. Xu and F. Zhao, Pedosphere, 2014, 24, 330.

19 I. Kamika and M. N. B. Momba, Water, Air, Soil Pollut., 2011, 223, 2525.

20 F. Yu, J. Zou, Y. Hua, S. Zhang, G. Liu and D. Zhu, Chemosphere, 2015, 138, 398.

21 A. A. de Souza Machado, K. Spencer, W. Kloas, M. Toffolon and C. Zarfl, Sci. Total Environ., 2016, 541, 268. 